\title{
The Political Economy of Mass Incarceration: An Analytical Model
}

\author{
Peter Temin*+
}

\section{Working Paper No. 56}

\author{
May 15, 2017
}

\begin{abstract}
This paper presents a model of mass incarceration in the United States, which has the largest proportion of its population imprisoned among advanced countries. The United States began to differ from other countries in the 1970s in response to changes in judicial policies. Although the Kerner Commission recommended integrating the black community into the larger American community, judicial policies went in the opposite direction. The model draws from several accounts of these changes and demonstrates that the United States has moved from one equilibrium position to another. It is driven by two equations, one for incarceration and one for

\footnotetext{
* MIT Department of Economics.

${ }^{+}$I thank David F. Weiner for introducing me to several papers and books on mass incarceration and Robert M. Solow for helping me understand the dynamics of differential equations. I also thank the Institute for New Economic Thinking for financial support.
} 
crime. It explains why the growth of prisoners has ceased in the last decade and what would be needed to return to the original equilibrium.

JEL Numbers: H1, K42, J78

Keywords: mass incarceration, prisons, crime, race 


\section{I: Introduction}

Mass incarceration is a major problem of the United States today that is largely invisible to us. Prisons are located in rural areas to save money and provide rural jobs, even though it makes family visits more difficult. And the effects of mass incarceration are largely ignored in political and social discussions. How many people know that one out of three African American men will go to prison at today's incarceration rates? And how many kids in urban public education are distracted by having a parent or a friend's parent in prison? These are problems that urgently need to be addressed, and this paper hopes to shed light on this unseen, but very important, problem (Bonczar, 2003; Johnson, 2009).

I have argued that we cannot improve urban education without reducing mass incarceration. Prisoners are not drawn randomly from the American population. Instead they come from poor urban areas where police activity is concentrated. Schoolchildren in those areas have relatives in prison or know classmates who have relatives in prison. It is hard for students to think about the long-term advantages of education if they cannot see how to can escape imprisonment in the meantime. In addition, most families with imprisoned members are poor and live in poor neighborhoods where schools are underfunded. Schools in these urban 'ghettos' need more resources than other schools, not less (Boston Indicators Project, 2016; Morsy and Rothstein, 2016; Temin, 2017).

The rate of incarceration in the United States stayed near one hundred people per 100,000 residents from 1925 to around 1980. The incarceration rate then rose rapidly for the next thirty years, although the rise slowed after 2000. The rise in state prison admissions and releases is shown in figure 1. The incarceration rate in prisons and jails in 2009 was over 700 per 100,000, while the incarceration rate in the European Union stayed near the American rate before 1980. The rates in Canada and Mexico stayed near 100 and 200, respectively, as well. The American incarceration rate now is the highest in the developed world, beating even Russia's incarceration rate of just under 600. A recent count found that the United States rate of incarceration recently stopped rising and fell in 2015 (Raphael and Stoll, 2013, 5-10; Carson and Anderson, 2016). 
Figure 1 looks like Piketty's opening graph in his book, Capital in the Twenty-First Century, and a similar graph in my book, The Vanishing Middle Class. These graphs showed the rise in the share of income accruing to the top ten and one percent of the American population, respectively. The only apparent difference is the flattening out of Figure 1 after 2000, which is important for my argument. The coincidence at the left-hand side of the curves is no accident; the rise in income inequality was caused by a variety of changes that resulted from a very active backlash to the Civil Rights Movement of the 1960s. The deviation at the right-hand side of the curves is, I argue here, is due to emergence of a new equilibrium for mass incarceration (Piketty, 2014; Temin, 2017).

I present a simple economic model to synthesize and unify several recent books on mass incarceration in America. Each of these books is an important contribution to the literature in its own right, but this model integrates the various contributions into a single story that shows the power - and the limitations - of policy to eliminate American mass incarceration.

The first book I explore was written by economists and is entitled Do Prisons Make Us Safer? As its title indicates, this edited volume focuses on the effects of incarceration on crime, since a reduction in crime presumably makes us safer. It climaxes with an effort to calculate the costs and benefits of mass incarceration, assuming that the effect of incarceration on crime is stable enough to provide a number. The second book, by the same authors, is entitled Why Are So Many Americans In Prison? It focuses on the rising incarceration rate in the past forty years and asks what the causes are. Note that the dependent variable to be explained differs between these books. The first book tries to explain the crime rate (safety), while the second book tries to explain mass incarceration (Raphael and Stoll, 2009; Raphael and Stoll, 2013).

The third book, written by a criminologist, is entitled Imprisoning Communities. It argues that mass incarceration can end up increasing the crime rate by destroying the social fabric of neighborhoods losing members to prison. It focuses attention on the factors increasing crime through changes in the community, not simply changes in individuals. The fourth book, written by the same author and a coauthor, is entitled The Punishment Imperative. It explains the growth of mass incarceration as a grand social experiment. Like the economists, these criminologists first asked about determinations of the crime rate and subsequently about the rate of incarceration (Clear, 2007; Clear and Frost, 2014). 
The fifth book was written by a lawyer and is entitled The New Jim Crow. It focuses on the racial composition of mass incarceration, viewing it as a form of social repression. Race is mentioned in the other books, but it deserves more emphasis. And the final book, entitled Locked In and also written by a lawyer, argues that the process of incarceration is very important. Our judicial system has changed to give prosecutors more power (Alexander, 2010; Pfaff, 2017).

The first insight from these books is that incarceration can cause crime to increase, not decrease, in the presence of mass incarceration. This non-intuitive proposal is supported by observing that mass incarceration reduces social and human capital in a neighborhood, leading to more criminal activity. The second insight is that mass incarceration may be in equilibrium in the United States today. Recent changes in criminal justice that increase the power of public prosecutors will be very hard to reverse. The purpose of synthesizing these contributions in an economic model is to make these insights more useful for criminologists and economists working in the fields of mass incarceration and social justice. I present the model and then use the model to explain the development of American mass incarceration since 1970, closing with suggestions for policy and future research.

\section{II: The Model}

These books identify two variables of interest in the study of mass incarceration: the crime rate, c, and the rate of incarceration, i. I describe their determinants in a set of equations. The first equation shows the crime rate as a function of the rate of incarceration.

$$
\mathrm{c}=\mathrm{f}(\mathrm{i})
$$

Although the equation is simple, the function, $\mathrm{f}(\mathrm{i})$, is complex. It summarizes the various effects of incarceration on the crime rate and leaves out all the other determinants of crime. Even so, it summarizes both personal and social responses to incarceration in $\mathrm{f}(\mathrm{i})$ to indicate a simple dynamic. When the crime rate, $c$, is above $\mathrm{f}(\mathrm{i})$, the crime rate tends to fall. And when $\mathrm{c}$ is below $\mathrm{f}(\mathrm{i})$, $\mathrm{c}$ tends to rise. When equation (1) holds, the crime rate, $\mathrm{c}$, is stable. 
When the rate of incarceration is low, putting more people in prison reduces the stable crime rate by forcibly taking wrong-doers away, but this effect diminishes as the rate of incarceration increases. When incarceration increases enough to be called mass incarceration, putting more people in prison increases the stable crime rate by reducing the human capital of prisoners and the social capital of local communities. A function determined by different forces at low rates than at high rates of incarceration cannot be linear. Clear realized this curvature existed and argued that it might require a cubic equation to represent how incarceration affects crime at different levels of i. At a zero rate of incarceration, there will still be some crime; our society is not so uniform and rigid that no one would dream of taking advantage of another. Only at a hundred percent rate of incarceration, would there be no crime, since no one would be able to commit a crime. Equation (1) reaches both axes of the two-dimensional graph at positive levels and has an overall negative slope.

But at some point on $\mathrm{f}(\mathrm{i})$, there is a section where the slope is positive, that is, where more incarceration leads to more crime. Equation (1) cannot be linear, as the slope cannot be constant. It cannot be quadratic because it eventually hits both axes and has to change slope more than once. A cubic equation is the simplest functional form that allows an overall decline to be interrupted by a positive rise. Figure 2 shows such a curve. I do not show where equation (1) reaches the axes in order to detail the part of the curve where the slope varies (Clear, 2007, $160-61)$.

There are lags in equation (1) to allow time for people and neighborhoods to change their behavior. In other words, we should expect to observe deviations from this equation. There might be a temporary crime wave, and there might be a slow convergence to equation (1) as affected communities change.

Clear summarized his insight in a summary paragraph: "U.S. prison populations have grown every year for over 30 years, and we have had for some time the highest incarceration rate in the world. Imprisonment in America is concentrated among young, poor-dominantly minority - men and (to a lesser extent) women who come from impoverished communities. The way these young people cycle through our system of prisons and jails, then back into the community, leaves considerable collateral damage in its wake. Families are disrupted, social 
networks and other forms of social support are weakened, health is endangered, labor markets are thinned, and - more important than anything else — children are put at risk of the depleted human and social capital that promotes delinquency. After a certain point, the collateral effects of these high rates of incarceration seem to contribute to more crime in these places. Crime fuels a public call for ever-tougher responses to crime. The increasing way in which the face of criminality is the face of person of color contributes to an unarticulated public sense that race and crime are closely linked. The politics of race and justice coexist malignantly, sustaining an ever-growing policy base that guarantees new supplies of penal subjects in a self-sustaining and self-justifying manner (Clear, 2007, 175).”

The second equation describes the behavior of $\mathrm{c}$ when it deviates from $\mathrm{f}(\mathrm{i})$. The constant is in the equation to allow this function to be used for the total crime rate, the violent crime rate or Part 1 crimes.

$$
\mathrm{dc} / \mathrm{dt}=\mathrm{a}[\mathrm{f}(\mathrm{i})-\mathrm{c}]
$$

The third equation turns to the second question raised by the books described earlier and shows how the sustainable rate of incarceration, i, varies with crime, c.

$$
\mathrm{i}=\mathrm{g}(\mathrm{c}) / \mathrm{r}
$$

Equation (3) answers the question: for a given crime rate, when will the incarceration rate be constant? The answer is when the number of convictions, $g(c)$, equals the number of releases, ri. Equivalently, when the prison population, i, equals the number of convictions times the length of sentence, $1 / \mathrm{r}$. The function, $\mathrm{g}(\mathrm{c})$, describes the sustainable imprisoning rate as the result of political activities that may change abruptly in the wake of political changes. In other words, changes in the government policies may be as important as movement along the function, $g(c)$, itself.

The function is taken to be linear for two reasons. The conventional analysis is that incarceration changes more or less proportionally with crime; the rate of incarceration is a constant times the crime rate. And changes in this constant are of great importance for the operation of this model. The sustainable rate of incarceration rises with the function that shows 
how the justice system takes people from committing crimes to serving time in prison and decreases with the rate of release from prison.

The fourth equation shows that the rate of incarceration increases over time when the number of people entering prison exceeds the release rate, $r$, times the rate of incarceration. The number of people going to prison is a function of the crime rate, and the number of people leaving is simply the release rate from prison times the proportion of people in prison:

$$
\mathrm{di} / \mathrm{dt}=\mathrm{g}(\mathrm{c})-\mathrm{r} \mathrm{i}
$$

The amount of incarceration is like water in a bathtub, with $g(c)$ being a faucet that fills the bathtub, and $r$, the release rate, being a drain that empties the bathtub. When $g(c)=r i$, the rate of incarceration is sustainable as shown in equation (3). Unlike equation (2), equation (4) is a mechanical relationship that tells how the rate of incarceration changes. The rate of incarceration is stable when these two rates are equal. The "faucet" describes how crime leads to incarceration through political decisions on policing, justice, and sentencing. The function, $\mathrm{g}(\mathrm{c})$, is affected by politics in addition to the crime rate. It resembles the accounting model used by the second book described earlier (Raphael and Stoll, 2009, 29-32).

The remaining question is how equation (3) appears on a graph of c and i. Equation (5) is derived from equation (3) by solving equation (3) to get $\mathrm{g}(\mathrm{c})=\mathrm{r}$ i and differentiating by $\mathrm{i}$ to get $g^{\prime}(c) d c / d i=r$. Rearranging yields equation (5).

$$
\mathrm{dc} / \mathrm{di}=\mathrm{r} / \mathrm{g}^{\prime}(\mathrm{c})
$$

If $g(c)$ is linear, then $g^{\prime}(c)$ is constant and measures the sensitivity of incarceration to the crime rate. When incarceration is insensitive to crime, that is, when there are alternatives to incarceration, the equation (5) is steep. When incarceration responds strongly to crime, then equation (5) is flatter.

Equations (1) and (5) are shown in figure 2. They cross at an equilibrium. Arrows show the direction of movement when out of equilibrium, dc/dt and di/dt, as defined by equations (2) and (4). Equation (1) is drawn as cubic curve falling at low and high incarceration with a rising section in the middle. The slope of the line defined by equation (5) varies with $r$ and is linear in 
the rate of incarceration, $g(c)$. Since both $r$ and g'(c) are positive constants, the line slopes upward.

Equations (2) and (4) describe the dynamics of this model when it is out of the equilibrium where the two curves cross. When $\mathrm{f}(\mathrm{i})>\mathrm{c}, \mathrm{dc} / \mathrm{dt}$ is positive, and when $\mathrm{f}(\mathrm{i})<\mathrm{c}$, $\mathrm{dc} / \mathrm{dt}$ is negative. When $\mathrm{g}(\mathrm{c})>\mathrm{ri}$, di/dt is positive, and when $\mathrm{g}(\mathrm{c})<\mathrm{ri}, \mathrm{di} / \mathrm{dt}$ is negative. As you can see from the arrows in figure 2, the intersection of the two curves represents a stable equilibrium. The line for $\mathrm{i}$ (equation (3)) needs to be steeper than the line for c (equation (1) when they cross for the equilibrium to be stable.

Equation (1) is behavioral and liable to have lags as behavior changes slowly. It is best to see this relationship as a long-run relationship that may not be observed exactly at all times. Equation (5), by contrast, is an exact relationship whereby the incarceration rate will adjust immediately after a change in judicial or police actions that increase $g(c)$ or a change in the length of sentences that reduce prison releases, $r$.

Clear talked of two interactions between $\mathrm{c}$ and $\mathrm{i}$, both background to equation (1). The first interaction is that incarceration reduces crime in a community by removing people engaged in criminal activity from the community. The second relation is that forcibly removing people from the community damages the internal organization of the community.

Taking people engaged in criminal activity out of a community reduces the crime rate and makes a community safer. This is a restatement of the common practice of sending a convicted person to prison. There is a presumption that a person who does not obey the law in a particular instance may be prone to operate outside the law at other times. This informal claim does not fit clearly into the two contrasting views of criminality that affect the history of American incarceration. One is that most criminals are the same as other people who have done illegal things; the other is that most criminals are different kinds of people than law-abiding ones. The United States seems to be committed at the moment to the second of these, which helps explain why we have mass incarceration. And the supposition that criminals can be identified by their skin color helps explain why prisons are disproportionally black (Alexander, 2010). 
These two views of prisoners depend on two views of prison's role: revenge or rehabilitation. The former role is relevant for the second view of American prisoners, which has become entwined with racism as the proportion of black prisoners has risen. The latter role is of concern to liberal observers, but it is not apparent in many prisons, and particularly not in for-profit prisons. As Charlie Baker, Governor of Massachusetts, said, "Prison is, as it should be, a punishment (Miller, 2017).”

There are diminishing returns in this positive effect of removing criminals. The arrest of one person may encourage others to act within the law. It might encourage others to hide their criminal activities more carefully. And if the arrested person led a group of lawbreakers, the group may lose cohesion after he or she is sent away. These factors vary among types of crimes and may not be strong in all cases. The presence of diminishing returns was confirmed by economists working on this topic: "Existing empirical work research on incarceration and crime for both the United States and other countries ... finds that crime-fighting effects diminish considerably as the incarceration rate increases. Specifically, as incarceration rates grow, the marginal impact on crime rates diminishes (Raphael and Stoll, 2013, 30).”

In contrast, the second effect of incarceration on the crime rate, by which more incarceration increases crime, increases with the number of people removed from the community. Clear identified several paths through which this effect operates: "In a discussion of public safety in the context of community life, five constructs provide useful insights for understanding how differences among communities contribute to differences in public safety. These constructs are human capital, social networks, social capital, collective efficacy, and informal social control (Clear, 2007, 75)."

Human capital is the result of education in economics studies, but Clear defined it more broadly. He included job skills, and social intelligence and ease. Education became an indicator, but not the full description of human capital. Human capital was distinguished from other forms of capital by being individual.

Social capital is the capacity of a person to call upon personal ties to advance a personal interest. It differs from human capital in describing the connections between people rather than the development of individuals. Economists are more comfortable with the concept of human 
capital than the concept of social capital as a focus on individuals is the hallmark of modern economics. Clear however stated that the two are tightly connected: "Social capital relies upon (and in turn promotes) human capital. It contextualizes human capital (and vice versa) because neighborhoods rich in social capital exert more control over individual residents, thus helping to produce more highly educated, employable and productive members of the community (Clear, 2007, 81).”

Social networks are the array of relationships that people have at home, with families and at work. They may extend further to friendships or other attachments that are looser than immediate companions. The unit of analysis is the strength of the ties between different people. Prisoners returning home often rely heavily on their family ties as they have weaker ties to the community and potential employers.

Collective efficiency is the capacity of a local neighborhood to come together and solve problems that affect them all. It requires agreement on what the problems are and how they might be solved as well as a shared interest in solving them.

Informal social control is the ability of the community to suppress deviance within the community. It is required to implement decisions coming from collective efficiency and to preserve the coherence of the neighborhood. It is diminished greatly by the removal and reentry of people by mass incarceration; they do not have the social networks needed for collective efficiency. After explaining these theories, Clear pulled them together in a model that suggested a cubic equation is needed to show the relation between incarceration and crime.

Economists recognize the first two of Clear's constructs, but they do not think much about the others. This is a result of disciplinary bias. Sociologists are interested in the informal controls that local groups use to maintain coherence in their lives and relationships. They detail these aspects of small-group interactions, while economists lump them into social capital. Clear's detail helps focus interest on neighborhoods, and it clarifies the complex shape of f(i).

The slope of $\mathrm{g}(\mathrm{c})$ is affected strongly by the internal structures of the American judicial system. Prosecutors have replaced judges and juries as the critical decision makers in American criminal justice. The laws that are visible to all are implemented by public prosecutors in the privacy of their offices. These prosecutors have used the laws to persuade accused individuals 
to plea bargain; a process that has become central to the growth of mass incarceration. The recent growth of prosecutor independence has made the judicial process far less sensitive to external forces than it was a generation ago, although it is responsive to changes in laws and popular sentiments. This pervasive change affects state and local judicial processes — almost all prisoners today are in state rather than federal prisons (Pfaff, 2017).

\section{III: Application}

Having explained the model, I now use it to increase our understanding of the rise of mass incarceration in the United States after 1980. Figure 3 provides a framework for the narrative to follow. I have drawn three examples of the line for incarceration in equation (3). The first line is the same as in figure 2, and represents the curve as it existed around 1965. It is labeled i1, and it represents an equilibrium incarceration rate typical of Western Europe, Canada and Mexico. The change to mass incarceration is seen as a two-stage process.

The crime rate jumped in the late 1960s, moving the United States off the equilibrium and significantly above it to point B. This crime wave cried out for policy changes, and the incarceration line moved in two stages. The first stage is a decline in the slope of the incarceration line that maintained the previous equilibrium. This curve is labeled i2. The second stage was a further decline in the slope of the incarceration rate which intersects the crime rate curve at several places. Only two of these crossings are stable, presenting the United States with a choice of very few prisoners and mass incarceration. This curve is labeled i3, and it is drawn to pass through B as well to reflect the effects of the crack epidemic of the 1980s. There was more crime, represented by a new move to point $B$, and a further decrease in the slope of the incarceration function. As shown in figure 1, incarceration began to rise.

The slope of the line i3 is small. Figure 4 shows that the increases in admission into prisons and release from prisons went together. Despite an increase in the length of sentences, it was not enough to change the rate of incarceration very much. The reason for the falling slope of $i 3$ was due to a change in g'(c) hidden in the judicial system; the low slope came from the increasing power of public prosecutors. The number of line prosecutors, that is, those that try cases, rose from 17,000 in 1970 to 20,000 in 1990 and to 30,000 in 2007. The number of public defenders did not rise, and the result was increasing power of public prosecutors. They used 
their power to seek plea bargains, and jurisprudence moved from the courtroom to the offices of public prosecutors. Prosecutors used their new power to increase the sensitivity of incarceration to the crime rate, dramatically reducing the slope of i3 (Pfaff, 2017, 129).

American society was in turmoil in the 1960s. There were many high-profile assassinations of prominent people: John F. Kennedy in 1963 and Martin Luther King and Robert F. Kennedy in 1968. And there were race riots in many cities around the country: Harlem in 1964, Watts and Chicago in 1965 and Newark, Detroit and many other cities in 1967. Crime suddenly had risen all over. People were scared, and President Johnson appointed a National Advisory Commission on Civil Disorders, known as the Kerner Commission, in 1967 to help understand what was going on.

The Kerner Commission's Report was rushed into publication for political reasons and soon was drowned out by concern over the Vietnam War. It however crystalized what was going on in a pithy conclusion: "What white Americans have never fully understood—but which the Negro can never forget - is that white society is deeply implicated in the ghetto. White institutions created it, white institutions maintain it, and white society condones it (Kerner Commission, 1968, Summary; Harris and Elkins, 1986, 19).”

The report also reported that the riots were caused in part by a revolution of rising expectations. The Civil Rights Movement of the 1960s led African Americans to hope for integration into the general society, but progress was slow. Observers of other attempted revolutions have noted that they often come when expectations rise faster than the anticipated outcomes appear. De Tocqueville, for example, noted that, "Evils which are patiently endured when they seem inevitable become intolerable when once the idea of escape from them is suggested." Historian Crane Brinton expanded this comment into a theory of revolutions in the 1930s (Kerner Commission, 1968, Chapter 5; De Tocqueville, 1856, 214; Brinton, 1938).

Consistent with this view, the report concluded that policies should be adopted to move toward a single integrated society: "Integration is the only course which explicitly seeks to achieve a single nation rather than accepting the present movement toward a dual society. This choice would enable us to at least begin reversing the profoundly divisive trend already so 
evident in our metropolitan areas—before it becomes irreversible (Kerner Commission, 1968, Chapter 16)."

But the Kerner Report was drowned out by the Vietnam War and the backlash to the Civil Rights Movement. Instead of reversing the divisive trend, public policies intensified it by seeking additional imprisonment and longer sentences for African Americans. The riots passed into history, but the urge to incarcerate altered the equilibrium shown in figure 2. Starting in the 1970s, state legislatures moved to shift from discretionary to structured sentencing rules. These changes were part of the increasing war on drugs, but their timing indicates that they also were reactions to the urban race riots of the preceding decade. They set the stage for the growth of incarceration, but they did not result in rising rates of incarceration in the 1970s as shown in figure 1 (Weiman and Weiss, 2009).

The policy changes that led to mass incarceration have been characterized as a regime change, signaling a change from regarding incarcerated people as ordinary people who have engaged in illegal acts to regarding them as different kind of people than others. Different kinds of people often were distinguished by skin color, and this racial content was imbedded in some of the new laws. The change also has been characterized as a grand social experiment which now has failed (Weiman, et al., in Bushway, et al., 2007; Clear and Frost, 2014).

This story is shown in figure 3 . The first movement is a spike in the crime rate during the late $1960 \mathrm{~s}$ in the urban riots. It is shown as a movement from point $\mathrm{A}$ to point $\mathrm{B}$, from the equilibrium to a point off of the incarceration curve. The crime rate reverted to the prior equilibrium in the 1970 s, but the slope of the incarceration function declined as arrests rose and releases from prison, $\mathrm{r}$, decreased as sentencing increased. These changes were to reduce lawlessness, although the spike in crime during the urban riots had come to a halt quickly by then.

The crack epidemic of the 1980s led to policy changes that combined the two movements of the $1970 \mathrm{~s}$. The changes originated in an attempt to reform the judicial process to lower prison terms, promote consistency among courts and encourage alternative sanctions to prison. By the time various bills were combined and transformed into the Sentencing Reform Act of 1984, however, the aim had shifted to become a part of the War on Drugs and the 
national toughness on crime. It was followed by a series of laws that translated the new, tough approach into detailed sentencing guidelines (Lynch, 2016, Chapter 2).

The Anti-Drug Abuse Act of 1986 was passed after a basketball player died from a drug overdose and Republicans accused Democrats of being soft on crime. Democrats wanted to take credit for an anti-drug program in the November elections, so the bill had to pass Congress by in October. That required action on the House floor in September, and committees had to finish their work before the August recess. Since the idea was born in July, committees had less than a month to develop the ideas, write the bills to carry out those ideas and get comments from the relevant government agencies and the public at large.

The House Judiciary Committee considered a new idea that was "tough on drugs" for the first time four days before the recess began. The idea was to create mandatory minimum sentences in drug cases, which had tremendous political appeal. It was a type of penalty that had been removed from federal law in 1970 after extensive and careful consideration. But no hearings were held on reviving this idea in 1986. No experts on the relevant issues, no judges, no one from the Bureau of Prisons or from any other office in the government provided advice on the idea before it was rushed through the committee and into law. After bouncing back and forth between the Democratic House and the Republican Senate as each party jockeyed for political advantage, the Anti-Drug Abuse Act of 1986 passed both houses a few weeks before the November elections (Sterling, 1999).

The new law mandated a minimum sentence of 5 years without parole for possession of 5 grams of crack cocaine, while it mandated the same only for possession of 500 grams of powder cocaine. This 100:1 disparity clearly criminalized blacks far more than whites as black crack users favored crack cocaine; Nixon's War on Drugs became even more firmly integrated into a new Jim Crow. The disparity was reduced to 18:1 in 2010, when the illegal possession of crack cocaine was increased to 28 grams ( 1 ounce) by the Fair Sentencing Act of that year. The larger disparity had continued for a quarter century, supported by the backlash from the Civil Rights Movement, Nixon's Southern Strategy, and the belief that black prisoners were inherently criminal — not ordinary people who had done criminal things (Raphael and Stoll, 2013, 115-20). 
The Anti-Drug Abuse Act of 1986 allowed prosecutors to seek a doubling of the mandatory minimum sentences is the defendant had a prior conviction. Another law passed in 1988 allowed prosecutors to ask for life imprisonment without parole for defendants who had two or more prior drug convictions. The result was that one out of three black men could expect to spend time in prison by the 1990s. The racial disparity between whites and blacks under the new rules can be seen in the contrast of between this estimate and the estimated one of seventeen white men who could expect incarceration. The War on Drugs became a New Jim Crow (Alexander, 2010; Bonczar, 2013; Bonczar and Beck, 1997; Lynch, 2016, 26).

Congress similarly determined the shape of another crime bill a decade later. President Clinton proposed another crime bill to allay fears of as the crime wave of the 1980 s reached its peak with a bill that would put 100,000 more police on the streets and expand prisons. These punitive measures were offset by a ban on assault weapons and a variety of social programs aimed at crime prevention and social intervention. Clinton's centrist approach gave solace to advocates of both punishment and rehabilitation.

The bill seemed on the way to passage when it was upset by racial conflict. One of the social programs in the bill provided for midnight basketball to occupy errant youth and reduce the danger they posed on the nighttime street. Midnight basketball rapidly became associated with helping black youths and a code word for racial benefits. It raised deeply entrenched images and ideas associating crime with young African-American men that heightened the threat of crime and raised serious questions about preventative programs. The social programs were stripped from the bill, and it passed containing only the punitive parts (Wheelock and Hartmann, 2007; Raphael and Stoll, 2013).

Federal laws were expanded in state laws that ranged from three-strike laws to harsh penalties for possession of small amounts of marijuana. The laws also shifted the judicial process from judges to prosecutors, from the courtroom to offices where prosecutors put pressure on accused people to plea-bargain. The threat of harsh minimum sentences gives prosecutors the option of reducing the charge to a lesser one if the accused is reluctant to languish in jail — if he or she is unable to make bail — and then face the possibility of long years in jail. And the shift of power was eased by the pattern of financing. Prosecutors are paid by localities, while the costs of prisons are borne by states. The trip to the penitentiary does not cost the prosecutor at all. "Instead of juries and trial judges deciding whether this or that 
defendant merits punishing, prosecutors decide who deserves a trip to the nearest penitentiary (Stuntz, 2011, 286).”

This new judicial system raised convictions and entries into prison as shown in Figure 4. As the figure shows, releases also rose. While these processes grew in tandem, the rise to mass incarceration was caused far more by the increase in criminal convictions than by increasing the length of incarceration. The increase in minimum sentences served as threats used by prosecutors to convince suspects to plead guilty to a lesser crime - and shorter prison stay. The number of inmates grew primarily from the increase in convictions rather than the length of sentences. "Few people in the criminal justice system are as powerful, or as central to prison growth, as the prosecutor (Pfaff, 2017, 127)."

Pfaff minimized the role of drug laws in mass incarceration on the grounds that most state prisoners were convicted of violent crimes. Only federal prisoners were predominantly convicted of drug violations. But the importance of public prosecutors and plea bargains contaminates this inference because the listed crimes in state prisons were produced in plea bargains. Since drug laws are so severe, plea bargains were driven toward lesser charges that did not fall under the drug laws. The results of the plea bargains do not indicate why prisoners were originally arrested and charged (Pfaff, 2017).

The importance of race is visible in many other ways. One example became wellknown when a defense attorney vividly described an attempt by prosecutors in Alabama to pin the murder of a white woman on a black man - the archetypal Southern practice. State officials used many types of illegal procedures to cajole witnesses to place the black man at the scene of the crime until the whole attempt came apart as the suspect's attorney exposed this tawdry pattern. The suspect spent several years in jail while being prepared for execution until he was finally freed (Stevenson, 2013).

The rise in crime during the 1980 s cocaine epidemic is represented by another movement from A to B in figure 3. (I assumed crime rose as much in the $1980 \mathrm{~s}$ as in the $1960 \mathrm{~s}$ for visual simplicity.) And the incarceration curve flattened even more as a result of the AntiDrug Abuse Act of 1986, rotating clockwise this time around point B. These movements eliminated the equilibrium at $\mathrm{A}$. 
There now are three places where the two curves intersect. They all represent equilibria, but the middle crossing is unstable. One is to the left of point B with less incarceration than point A. But, as shown in figure 2, the dynamics of the model push for more incarceration at point $\mathrm{B}$, representing the urge to incriminate more and more. Incarceration then increased until it came to rest at the equilibrium far to the right of point $\mathrm{B}$ at point $\mathrm{C}$. This is a stable equilibrium, and there was no mention of any program to move from it in the presidential campaign of 2016.

The crack epidemic and the resulting legislative changes that increased jail times are part of the story of increasing incarceration. But multivariate regressions using cocaine deaths as an index of the epidemic fail to show any effect of the epidemic on the smooth rise in incarceration shown in figure 1. The effects of policy changes in $\mathrm{g}(\mathrm{c})$ increased the prison population only after delays that smoothed out the curve, making it difficult to identify econometrically a single cause of mass incarceration. The regression results fit the model more closely than the historical narrative it purports to explain (Raphael and Stoll, 2013, 195-98).

The model distinguishes a change in the equilibrium from the movements of $\mathrm{c}$ and $\mathrm{i}$. As just explained, political events and changes in the judicial system in the 1980s changed the slope of $g(c)$, which moved the equilibrium but did not have any discernable effect on the variables until the forces shown in figure 2 worked for a while. Equations (2) and (4) assert that the approach to a new equilibrium will be faster when it starts further from the equilibrium. The slower growth and the hints of lower prison inmates in recent years represent the slowing down of the rate of incarceration close to the equilibrium.

\section{IV: Conclusions}

Mass incarceration is a blot on American democracy. It has mushroomed to the point where we look more like the kleptocracies of Eastern Europe and the Middle East than the democracies of Western Europe. Yet it vanished from political discussions in campaigns in the 2016 election. We need to focus on other aspects of the results. And the model indicates that it will be hard to dislodge ourselves from the new equilibrium of mass incarceration. 
The aim of policies to reduce mass incarceration is to increase the slope of $i 3$, that is, $\mathrm{r} / \mathrm{g}^{\prime}(\mathrm{c})$. A reduction in the rate at which crime increases incarceration, that is, a movement in $g^{\prime}(c)$ that results in a fall in $g(c)$, is the most effective policy. A start was made in the Fair Sentencing Act of 2010, but more progress does not look likely any time soon. If $\mathrm{r} / \mathrm{g}^{\prime}(\mathrm{c})$ paralleled line i 2 instead of following the current i3 in figure 3 , the equilibrium of mass incarceration at point $\mathrm{C}$ would vanish. The dynamics of the model imply that the forces described here would move the penal system toward point A.

Even more important than changing laws to reduce $\mathrm{g}(\mathrm{c})$ is changing the incentives for public prosecutors to cut plea deals and send accused people to prison. One way is to increase funds for public defenders to link the unopposed actions of prosecutors. Another is to use monetary incentives to induce prosecutors to focus more on serious defendants. Providing plea bargaining guidelines patterned after the New Jersey guidelines also will help. And obtaining more data about what happens in the process of plea bargaining can help us to design other levers to ease the urge of prosecutors to incarcerate. "It will not be easy. Reform will require prodigious and sustained effort, a both the grassroots and political elite levels (Pfaff, 2017, 205).”

Reducing convictions will be far more important than reducing the length of prison stays in lowering the incarceration rate. Better treatment of ex-felons would enable them to get better jobs, earn a living and not return to jail as often. And education within prisons, while not as good as education outside, also might help released prisoners to exist legally after release in addition.

Drawing back from the draconian guidelines set up in 1986 has been slow and difficult. The Fair Sentencing Act of 2010 reduced sentences for some offences and softened the racial discrimination, but a more recent attempt to go further in the Sentencing Reform and Corrections Act of 2015 did not pass (US Congress, 2015-16).

Both political parties were engaged at different times in legislation that gave rise to mass incarceration. It would seem likely that they could get together to try to reduce the rate of incarceration, but the prospects are not good. The reduction of incarceration always has some risks, and political figures are very risk averse. Some people want to reduce the cost of prisons 
to help fund other activities, but they have not produced many proposals to accomplish this goal or how to allocate the gains.

More difficult is the effort to treat felons better after their release to reduce the vicious cycle of prison release, crime and reincarnation. This change has to deal with potential employers' attitudes. They are afraid of employing ex-felons because they do not know if they can trust them. They do not want convicted felons to handle valuable merchandise or to interact with other employees that might lead to crimes. States also bar ex-felons from many jobs, and the applicants often have low human and social capital (Bushway, Stoll and Weiman, 2007).

The interaction of these problems and race has been illuminated by experiments with job applications. Efforts have been made in some states to "ban the box," that is, to avoid telling employers that the applicant has been in prison. Deprived of this information, potential employers appear to use statistical discrimination. Knowing the racial composition of prisons, they consider that a black job applicant is more likely to be a convicted felon than a comparable white applicant. Banning the box did not improve prisoners' chance to get a job; instead it changed discrimination on prison history to racial discriminations (Pager, 2007).

Education within prisons should help prisoners to be better people on their release, but it is unlikely to help them get a job in our current economy. Employment is determined by membership in large demographic groups, and it is hard for an individual to stand out for employment. And this difficulty is magnified, as Clear reminded us, by the lack of social capital in the communities ex-prisoners return to. There are few friends to recommend the job seeker for a job and possibly even few friends who have jobs and know people in any business that offers stable employment.

It took over 30 years to get into our current equilibrium of mass incarceration; we may not be able to get out of it in lesser time. And current policies in a closely related field do not encourage optimism. The federal government spends more on immigration enforcement than on all federal criminal law enforcement agencies combined, more than the spending for the FBI, Drug Enforcement Administration, Secret Service, U.S. Marshals Service and Bureau of Alcohol, Tobacco, Firearms and Explosives, combined. Much of this money goes to house people waiting for judicial hearings, which apparently did not increase enough to deal with 
increased enforcement of immigration rules. Detainees are housed in containment facilities that are increasingly run by for-profit prison companies. These facilities house immigrants, while mass incarceration typically houses citizens. They focus on Latinos rather than blacks, and they are largely separate from the War on Drugs. They nevertheless reinforce the image of inborn criminality and complicate the problem of justice and prison reform within the United States (Meissner, et al., 2013).

The Trump Administration is blurring the distinction between these two systems because the rapidly increasing number of immigration inmates is forcing the Administration to look for space in existing jails. Illegal immigrants are fitting into mass incarceration as jail prisoners awaiting government action, although the immigrants are in a civil procedure that could end in deportation while the prisoners awaiting trials are in criminal procedures leading to possible prison sentences.

The Clinton, Bush and Obama administrations tried to separate these two groups by adding specific requirements for the treatment of immigration detainees. These standards grew into more than 400 pages specifying, for example, the number of toilets available for the detainees. The Trump Administration replaced these requirements with much shorter list of general questions, such as whether the facility is "clean and in good repair," to persuade local officials who run jails to provide accommodations for immigrants. The changes also appeal to companies operating jails for profit; over half of immigration detainees are in private jails, contrasting with far lower proportions of criminal detainees held in private jails. As one Ohio sheriff who had about 300 inmates facing a mix of criminal and immigration charges said, "Jail is jail (Dickerson, 2017)." 


\section{References}

Alexander, Michelle, The New Jim Crow: Mass Incarceration in the Age of Colorblindness (New York: New Press, 2010).

Bonczar, Thomas P., "Prevalence of Imprisonment in the U. S. Population, 1974-2001,” U.S. Department of Justice, Bureau of Justice Statistics, August 2003, NCJ 197976.

Bonczar, Thomas P., and Allen J. Beck, "Lifetime Likelihood of Going to State or Federal Prison,” U.S. Department of Justice, Bureau of Justice Statistics, March 1997, NCJ 160092.

Boston Indicators Project, “The Geography of Incarceration,” The Boston Foundation, 2016.

Brinton, Crane, The Anatomy of Revolution (New Jersey: Prentice Hall, 1938).

Bushway, Shawn, Michael A. Stoll and David F. Weiman (eds.), Barriers to Reentry: The Labor Market for Released Prisoners in Post-Industrial America (New York: Russell Sage Foundation, 2007).

Carson, E. Ann, and Elizabeth Anderson, "Prisoners in 2015,” U.S. Department of Justice, Bureau of Justice Statistics, December 2016, NCJ 250229.

Clear, Todd R., Imprisoning Communities: How Mass Incarceration Makes Disadvantaged Neighborhoods Worse (New York: Oxford University Press, 2007).

Clear, Todd R., and Natasha A. Frost, The Punishment Imperative: The Rise and Fall of Mass Incarceration in America (New York University Press, 2014).

De Tocqueville, Alexis, The Old Regime and the Revolution (Paris, 1856), Book 3, Chapter 4.

Dickerson, Caitlin, “Trump Plan Would Curtail Protections for Detained Immigrants," New York Times, April 13, 2017.

Johnson, Rucker T., "Ever-Increasing Levels of Incarceration and the Consequences for Children," in Raphael and Stoll, 2009, pp. 177-206. 
Kerner Commission, The 1968 Report of the National Advisory Commission on Civil Disorders (New York: New York Times Company, 1968).

Lynch, Mona, Hard Bargains: The Coercive Power of Drug Laws in Federal Court (New York: Russell Sage Foundation, 2016).

Meissner, Doris, Donald M. Kerwin, Muzaffar Chishti, and Claire Bergeron, Migration Enforcement in the United Sates: The Rise of Formidable Machinery (Washington, DC: Migration Policy Institute, 2013).

Miller, Joshua, “Mass. Officials Unveil Plan to Prevent People from Returning to Jail," Boston Globe, February 21, 2017.

Morsy, Leila, and Richard Rothstein, “Mass Incarceration and Children's Outcomes: Criminal Justice Policy is Education Policy,” Economic Policy Institute Report 118615, December 15, 2016. Available at: http://www.epi.org/publication/mass-incarcerationand-childrens-outcomes/

O'Flaherty, Brendan, "Race May be Pseudo-Science, But Economists Ignore it at their Peril," Institute for New Economic Thinking, January 6. 2017. Available at https://www.ineteconomics.org/perspectives/blog/race-may-be-pseudo-science-buteconomists-ignore-it-at-their-peril Accessed January 12, 2017.

Pager, Devah, Marked: Race, Crime, and Finding Work in an Era of Mass Incarceration (Chicago: University of Chicago Press, 2007).

Pfaff, John F., Locked In: The True Causes of Mass Incarceration-and How to Achieve Real Reform (New York, Basic Books, 2017).

Piketty, Thomas, Capital in the Twenty-First Century (Cambridge: Harvard University Press, 2014).

Raphael, Steven, and Michael A. Stoll (eds.), Do Prisons Make Us Safer? The Benefits and Costs of the Prison Boom (New York: Russell Sage Foundation, 2009). 
Raphael, Steven, and Michael A. Stoll, Why Are So Many Americans in Prison? (New York: Russell Sage Foundation, 2013).

Sterling, Eric E., "Drug Laws and Snitching: A Primer,” Frontline, 1999. Available at http://www.pbs.org/wgbh/pages/frontline/shows/snitch/primer/

Stevenson, Bryan, Just Mercy: A Story of Justice and Redemption (New York: Speigel and Grau, 2015).

Stuntz, William J., The Collapse of American Criminal Justice (Cambridge, MA: Harvard Universtiy Press, 2011).

Temin, Peter, The Vanishing Middle Class: Prejudice and Power in a Dual Economy (Cambridge: MIT Press, 2017).

US Congress, "S.2123: Sentencing Reform and Corrections Act of 2015." Available at https://www.congress.gov/bill/114th-congress/senate-bill/2123

Weiman, David F., Michael A. Stoll, and Shawn Bushway," The Regime of Mass Incarceration: A Labor-Market Perspective,” in Bushway, Stoll and Weiman, 2007, pp. 29-79.

Weiman, David F., and Christopher Weiss," The Origins of Mass Incarceration in New York States: The Rockefeller Drug Laws and the Local War on Drugs," in Raphael and Stoll, 2009, pp. 73-116.

Wheelock, Darren, and Douglass Hartmann, "Midnight Basketball and the 1994 Crime Bill Debates: The Operation of a Racial Code," Sociological Quarterly, 48, 315-42 (2007). 


\section{Figure 1}

\section{Incarceration rate, 1925-2009}

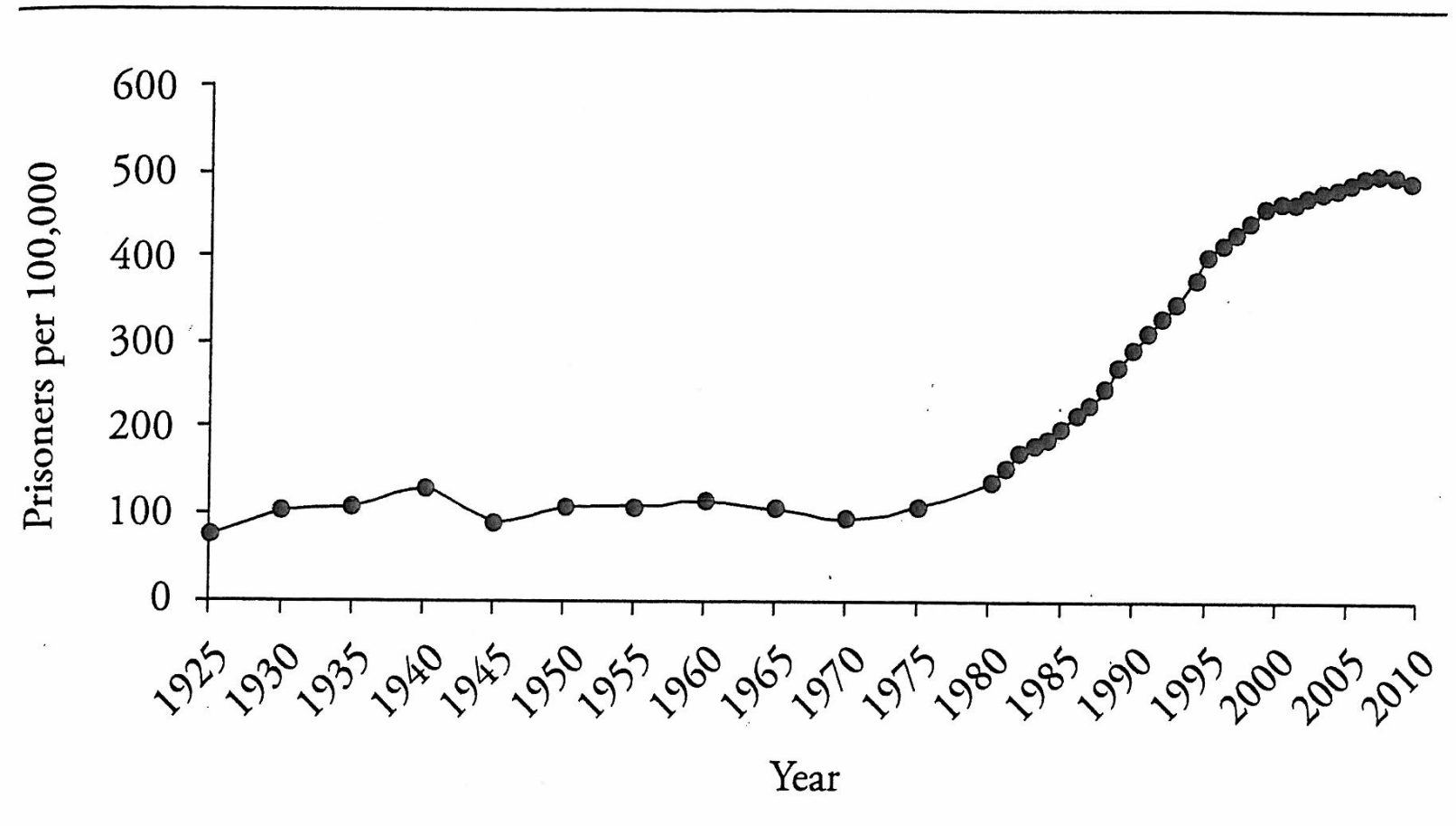

Source: Authors' compilation based on Bureau of Justice Statistics, National Prisoner Statistics (various years).

Source: Raphael and Stoll, 2013, p. 5. 
Figure 2

Curves showing the initial stable equilibrium

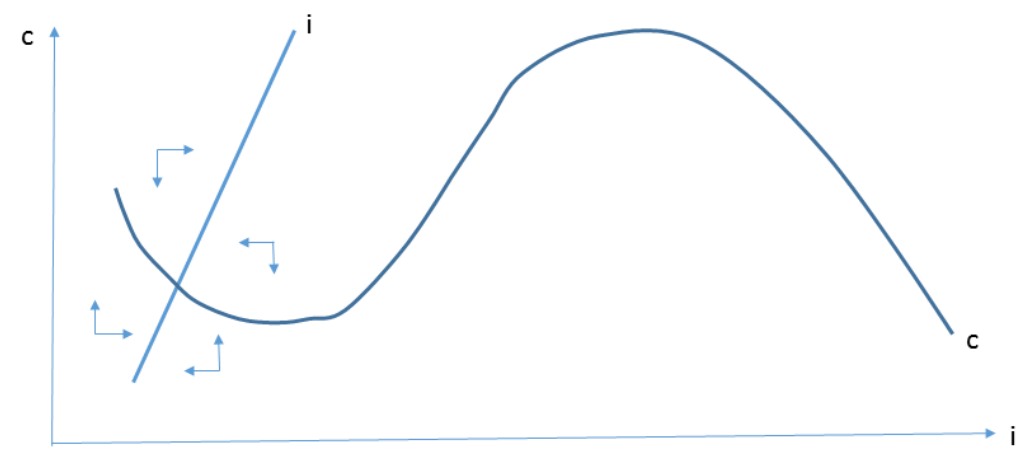




\section{Figure 3}

Curves showing two stable equilibria

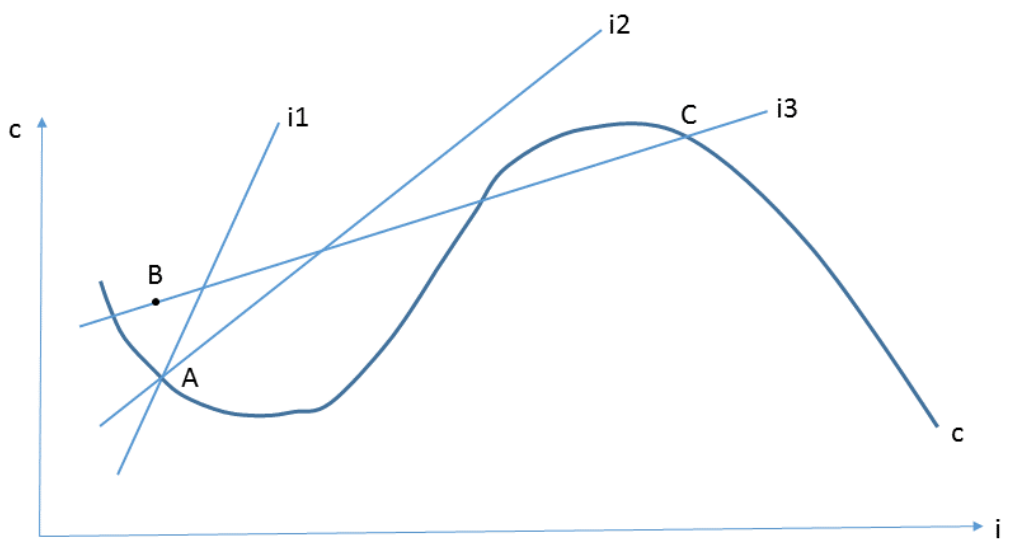


Figure 4

Admissions and Releases to US Prisons

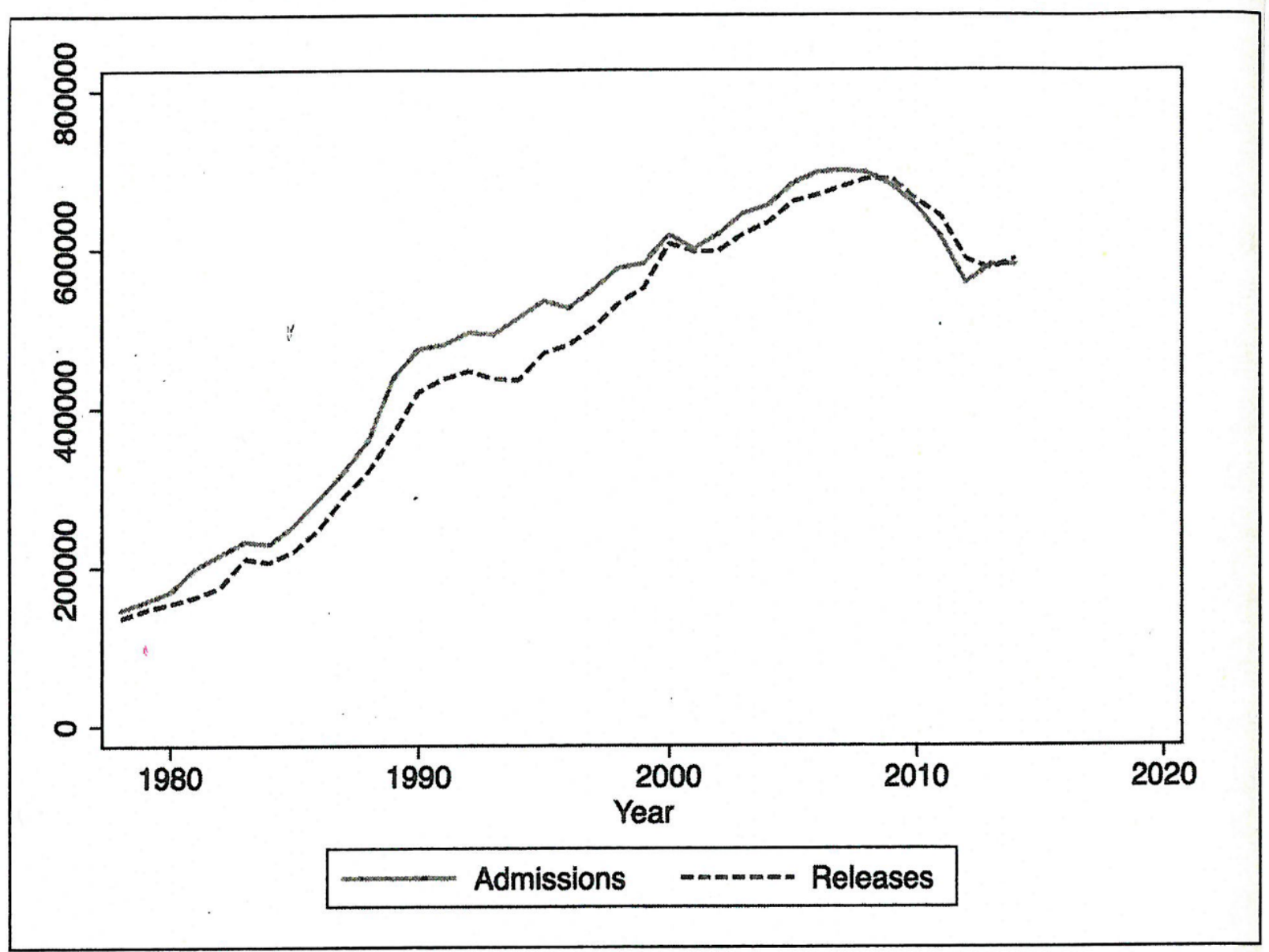

Source: US Department of Justice, Bureau of Justice Statistics, "Data Collection: NPS Program," www.bjs.gov/index.cfm?ty=dcdetail\&wd=269.

Source: Pfaff, 2017, 58. 